\title{
气候和人类活动对典型岩溶地下河系统 径流年际变化的影响
}

\author{
王赛男 ${ }^{1,2}$, 李建鸿 ${ }^{2}$, 蒲俊兵 ${ }^{2}$, 霍伟杰 ${ }^{2}$, 张 陶 $^{2}$, \\ 黄思宇 ${ }^{2}$, 袁道先 ${ }^{1,2}$
}

(1. 重庆市岩溶环境学重点实验室, 西南大学地理科学学院, 重庆 400715; 2. 中国地质科学院岩溶地质研究所/自然资源部、广西岩溶动力学重点实验室,桂林 541004)

\begin{abstract}
摘要: 为揭示气候变化与人类活动对岩溶地下河系统年径流量的影响, 以南洞地下河为研究 对象, 利用其1972-2014年的径流量、降水量和蒸散量数据, 分析其年际变化特征。研究结果表 明: 研究期内径流、降水和蒸散均呈现波动减少的趋势。其中流域内径流整体以 0.014 亿 $\mathrm{m}^{3} / \mathrm{a}$ 的 速度减少,降水整体以 $3.14 \mathrm{~mm} / \mathrm{a}$ 的速度减少, 蒸散整体以 $7.94 \mathrm{~mm} / \mathrm{a}$ 的速度减少。通过有序聚 类法和 Mann-Kendall 法综合确定出径流、降水的突变年份为 2002 年、2008年。通过累积量斜 率变化率比较法, 定量分解了不同时期气候与人类活动对径流变化影响的贡献率: 综合考虑降 水和蒸散因素, 以人类活动轻微的 $\mathrm{T}_{1}$ (1972-2002 年) 阶段为基准期, 气候变化对径流减少的贡 献率在 $\mathrm{T}_{2}$ (2003-2008 年)、 $\mathrm{T}_{3}(2009-2014$ 年) 时期分别为 $-86.68 \% 、 35.92 \%$, 人类活动对径流减少 的贡献率在 $\mathrm{T}_{2} 、 \mathrm{~T}_{3}$ 阶段分别为 $186.68 \%$ 、64.08\%。可见, 人类活动是南洞地下河流域径流量年际 变化的主导因素, 其中生活、生产的直接耗水和土地利用/土地覆被变化影响下径流过程的变 化,共同影响着径流年际变化。
\end{abstract}

关键词: 气候变化;人类活动;径流量;累积量斜率变化率比较法;南洞地下河

全球气候变化与区域人类活动对环境和水资源有显著影响 ${ }^{[1-2]}$ 。由于气候变化改变了 降水量、蒸发量, 影响了水循环过程, 进而驱动径流量等水文要素的变化, 因此气候变 化被认为是影响河川径流变化的驱动力之一 ${ }^{[3-4]}$ 。受自然和人为双重因素的影响，许多地 区河川径流量出现明显的减少趋势 ${ }^{[3-6]}$ 。此外，全球人口增长导致全球水需求的总体增 长，造成供水方面的额外人为压力 ${ }^{[7]}$ 。

量化气候变化和人类活动对径流变化的影响是当前水文、水资源学研究的热点，对 流域管理具有重要意义, 但对该问题的研究主要集中在地表河流, 而对岩溶地下河系统 的研究较缺乏 ${ }^{[3,8-10]}$ 。据统计, 全球淡水资源量约 0.35 亿 $\mathrm{km}^{3} / \mathrm{a}$, 其中地下淡水资源量约 0.105 亿 $\mathrm{km}^{3} / \mathrm{a}$ ，占全球淡水资源量的 $30.1 \%{ }^{[11]}$ 。中国地下水资源量约 8000 亿 $\mathrm{m}^{3} / \mathrm{a}$ ，其中岩 溶水约 2000 亿 $\mathrm{m}^{3} / \mathrm{a}$, 占地下水资源量的 $1 / 4$, 是重要的水资源 ${ }^{[2]}$ 。在中国南方岩溶区, 地 下水资源主要赋存于相对独立的地下河系统，它们是当地水资源开发利用的主要甚至唯一

收稿日期：2018-09-01；修订日期：2018-12-25

基金项目：国家重点研发计划课题（2016YFC0502501）；国家自然科学基金项目（41572234）；广西自然科学基金 项目 (2017GXNSFFA198006)

作者简介：王赛男（1995- ，女，四川彭州人，硕士，研究方向为岩溶环境与全球变化。

E-mail: sainanwang00@163.com

通讯作者：蒲俊兵（1982-), 男, 四川渠县人, 博士, 研究员, 研究方向为岩溶环境、岩溶水文地球化学等。

E-mail: junbingpu@karst.ac.cn 
对象 ${ }^{[13]}$ 。因此，掌握地下河径流变化规律以及影响因素对岩溶地区流域生态环境和社会 经济可持续发展有重要意义。但是, 地下水文过程作用机理复杂, 是当今地球关键带生态 水文学研究的主要科学问题之一 ${ }^{[14]}$ 。受制于特殊的岩溶地质条件, 定量分解气候与人类活 动对地下河径流变化的影响更是一个难点。王随继等 ${ }^{[3}$ 提出的累积量斜率变化率比较法, 定量分解了黄甫川流域气候和人类活动对径流变化的贡献率，被广泛应用到黄河流域 ${ }^{[1]} 、$ 松花江流域 ${ }^{[5]}$ 和后寨河流域 ${ }^{[10]}$ 。本文尝试利用累积量斜率变化率比较法分析中国南方大型 岩溶地下河——南洞地下河流域气候和人类活动对径流量变化的影响, 进一步揭示地下河 流域水资源的变化特征，为地下河水资源的合理调控提供重要科学依据。

南洞地下河流域位于云南省红河州蒙自市、开远市和个旧市境内, 是西南地区超大 型地下河。流域内广泛分布三叠系个旧组碳酸盐岩, 岩溶发育强烈、生态环境脆弱、石 漠化严重。目前针对流域的研究主要集中在流域地貌特征 ${ }^{[16-17]}$ 、地下河发育模式 ${ }^{[16,18]}$ 、石 漠化演变特征 ${ }^{[19]}$ 、地下河水质变化 ${ }^{[20]}$ 等方面，但针对流域气候和人类活动对径流变化影 响的研究较少 ${ }^{[21-22]}$ 。本文利用南洞地下河流域 1972-2014年的径流量、降水量和蒸散量数 据, 分析其径流年际变化特征, 利用有序聚类法和 Mann-Kendall 法识别流域内径流和降 水的突变年份, 并以此划分出径流和降水变化的不同阶段。利用累积量斜率变化率比较 法定量分解不同时期气候与人类活动变化对径流年际变化的贡献率，以加强对南洞地下 河流域水资源演变的认识，为流域内水资源合理开发、保护提供科学指导。

\section{1 研究方法与数据来源}

\section{1 研究区概况}

南洞地下河流域（图 1）位于云南省 红河州蒙自市、开远市和个旧市境内， 属珠江流域红水河上游南盘江水系。流 域面积约 $1018 \mathrm{~km}^{2}$, 多年平均径流总量为 2.59 亿 $\mathrm{m}^{3} / \mathrm{a}$, 是西南地区第三大地下河。 位于流域西北开远市境内的南洞口是南洞 地下河的常年出水口, 出水量占整个地下 河流域总径流量的 $80 \%{ }^{[23]}$ 。地下水从南洞 口出露后成为地表河, 又称南洞河, 南洞 河长约 $6 \mathrm{~km}$, 在开远市仁者村注人泸江。

从地质构造上看, 南洞地下河流域位 于康滇菱形板块东南角, 由于受西北、近 南北两条断裂和红河大断裂带的影响, 流 域内形成岩溶高原、断陷盆地、盆间丘陵 三种不同的地质地貌景观 ${ }^{[16,18]}$ 。岩溶高原 高程 1800 2000 m左右, 最高处大黑山顶 高程 $2700 \mathrm{~m}$ 左右, 主要由三叠系个旧组灰 岩组成, 溶丘洼地、漏斗等岩溶形态十分 发育。断陷盆地呈南北向分布, 高程

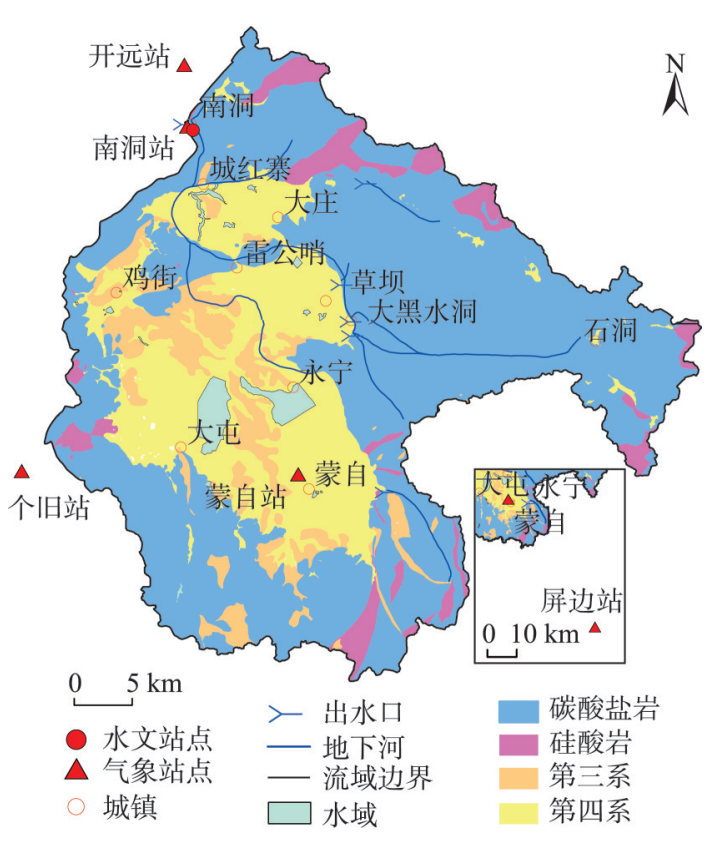

图 1 南洞地下河流域水文地质简图 (改自蒋勇军等 ${ }^{[20]}$ )

Fig. 1 Schematic hydrogeologic map in the Nandong subterranean river catchment (After Jiang Yongjun et al ${ }^{[20]}$ ) 
1260 1310 m左右，广泛分布着第三系泥灰岩、泥岩及第四系粘土、砂质粘土等。盆地 内地势平坦，耕地连片，人口集中。盆间丘陵，高程 1400 1500 m左右，主要为第三系泥 灰岩或三叠系个旧组碳酸盐岩组成。在盆地周边分布众多的落水洞、竖井等。由于垂直 差异明显, 盆地内年降雨量在 $800 \mathrm{~mm}$ 左右, 在高原山区达 $1200 \mathrm{~mm}$ 左右, 主要集中在 6-9 月，11月到次年 4月干燥少雨, 干湿季分明 ${ }^{[16]}$ 。复杂的地质构造条件, 造就复杂的地 下岩溶管道系统。南洞地下河由多条地下河组合叠置而成, 个旧组灰岩为主要含水层 ${ }^{[16]}$, 岩溶水为区内主要地下水类型。地下水补给主要是降雨补给和地表水通过洼地内落水洞 汇人地下河系统。虽然地下水位较深、开采难度大, 但对于地表水严重缺乏的蒙自盆 地，其开发潜力巨大。

\section{2 数据来源}

本文所用数据为南洞地下河流域 1972-2014年流量、降雨量和蒸散量数据, 涉及到 5 个气象站和一个水文站。地下河流量数据, 由位于南洞地下河出口的国家水文观测站 $\left(23^{\circ} 38^{\prime} 50^{\prime \prime} \mathrm{N}, 103^{\circ} 17^{\prime} 47^{\prime \prime} \mathrm{E}\right)$ 获取。流域年降水量数据（1972-2014年），通过 ArcGIS 10.2 克里金插值法插值统计而得，具体气象站包括蒙自站、个旧站、开远站、屏边站 (数据源于中国气象数据网: http://data.cma.cn/)、南洞站（数据源于南洞国家水文观测 站，降水数据收集到1986年)。

蒸散量数据只搜集到蒙自站蒸散量数据，因此通过数学方法间接获取整个流域的蒸 散量。具体方法是: 将流域内蒙自站降水数据 $x(\mathrm{~mm})$ 与插值统计后的流域平均降水 $y$ ( $\mathrm{mm})$ 进行相关分析得到如下公式:

$$
y=0.83 x+222.94, R^{2}=0.85, P<0.01
$$

数据显示蒙自站的降水量与整个流域的降水量有非常高的相关性，且显著性高，因 此推测蒙自站蒸散量与整个流域蒸散量也存较高的相关性，因此将 1972-2014年蒙自站的 蒸散数据分别代人式 (1), 得到新系列的蒸散数据, 代替整个流域的蒸散情况。

\section{3 研究方法}

\subsection{1 突变点识别}

为分析气候变化与径流变化的特征及原因，通过寻找突变时间点将气候因子与径流 进行阶段划分。有序聚类法和 Mann-Kendall法是气象、水文学中识别突变点的有效方 法，本文将使用这两种方法综合判别降水与径流变化的突变年份。

有序聚类法实质是以同类之间离差平方和较小的原则来寻找有序数据序列的最优分 割点 ${ }^{[5,24]}$ 。Mann-Kendall 法是检验序列是否存在突变的非参数检验法。对于一个序列, 计 算其序列统计量 $U$, 它是所有对偶中满足后者大于前者的对偶个数和后者小于前者的对 偶个数之差。进一步计算序列正向 $\left(U F_{K}\right)$ 和反向 $\left(U B_{K}\right)$ 的对偶统计量序列，画在同一 张图上, 如果两个曲线交点落在某显著水平接受域内, 则认为该交点（时刻）存在突变 趋势 ${ }^{[8,25]}$ 。具体方法详见参考文献 [5]、[8]、[24]、[25]。

\subsection{2 累积量斜率变化率比较法}

累积量斜率变化率比较法（Slope Change Ratio of Cumulative Quantity, SQRCQ) ${ }^{[3,5,10,15]}$ 的原理是, 如果流域中径流量变化只受降水量变化的影响, 那么同一时期累积径流量 一年份相关关系的斜率变化率应该等于累积降水量一年份的斜率变化率，这时降水量对 径流量变化的贡献率就是 $100 \%$ 。降水量对径流量变化的贡献率总是等于累积降水量斜率 
的变化率与累积径流量斜率变化率的比值 ${ }^{[3,5,15]}$ 。

首先以拐点为界，对降水、蒸散和径流的年际累积量与年份做相关分析，得出一元 线性关系式如下:

$$
y=k x+b
$$

式中： $k$ 为该时段降水、蒸散和径流一年份的斜率。假设在拐点前后累积径流量的斜率分 别是 $S_{R b 、} S_{R a}$, 则累积径流量斜率变化率如下:

$$
R_{S R}=100 \times \frac{\left(S_{R a}-S_{R b}\right)}{S_{R b}}=100 \times\left(\frac{S_{R a}}{S_{R b}}-1\right)
$$

如果拐点前后累积降水量的斜率分别是 $S_{P b} 、 S_{P a}$ ，则累积降水量斜率变化率如下：

$$
R_{S P}=100 \times \frac{\left(S_{P a}-S_{P b}\right)}{S_{p b}}=100 \times\left(\frac{S_{P a}}{S_{P b}}-1\right)
$$

如果在拐点前后累积蒸散量的斜率分别是 $S_{E b} 、 S_{E a}$, 则累积蒸散量斜率变化率为:

$$
R_{S E}=100 \times \frac{\left(S_{E a}-S_{E b}\right)}{S_{E b}}=100 \times\left(\frac{S_{E a}}{S_{E b}}-1\right)
$$

式中: $R_{S R} 、 R_{S P} 、 R_{S E}$ 为正, 则斜率变大, 表示径流、降水、蒸散量呈增加趋势; 为负, 则 斜率变小, 表示径流、降水、蒸散量呈减少趋势。降水量变化对径流量变化的贡献率 $C_{P}$ (\%) 可表示为:

$$
C_{P}=100 \times\left(R_{S P} / R_{S R}\right)
$$

由于蒸散量增加会加剧径流量的消耗，蒸散量减少径流损耗也减少。因此蒸散量与 径流量为负相关关系。那么蒸散量对径流量变化的贡献率 $C_{E}(\%)$ 可表示为:

$$
C_{E}=-100 \times\left(R_{S E} / R_{S R}\right)
$$

此时气候变化（降水和蒸散）对径流变化的贡献率 $C_{N}(\%)$ 可表示为:

$$
C_{N}=C_{P}+C_{E}
$$

人类活动对径流变化的贡献率 $C_{H}(\%)$ 可表示为:

$$
C_{H}=100-C_{N}
$$

\section{2 结果分析}

\section{1 年径流量、降水量和蒸散量变化特征}

南洞地下河流域 1972-2014年降水量、蒸散量和径流量年际变化趋势如图 2 所示，研 究期内南洞地下河流域年径流量、降水量和蒸散量呈明显的波动减少趋势。在研究期 内，南洞地下河流域多年平均径流量为 2.59 亿 $\mathrm{m}^{3}$ ，其中 1978 年径流量达 3.54 亿 $\mathrm{m}^{3}$ ，为径 流最大年份， 1980 年径流量为 1.42 亿 $\mathrm{m}^{3}$ ，为径流量最小年份，流域径流量整体以 0.014 亿 $\mathrm{m}^{3} / \mathrm{a}$ 的速度减少。流域多年平均蒸散量为 $1432.16 \mathrm{~mm}$, 其中 1980 年蒸散量达 $1849.76 \mathrm{~mm}$ ，为蒸散量最大年份，2000年蒸散量只有 $1160.59 \mathrm{~mm}$ ，为蒸散最少年份，流 域内蒸散量整体以 $7.94 \mathrm{~mm} / \mathrm{a}$ 的速度减少, 下降趋势明显。流域多年平均降水量为 $912.53 \mathrm{~mm}$ ，其中 1981 年降水 $1204.02 \mathrm{~mm}$ ，为降水最多年份，1980年降水 $639.67 \mathrm{~mm}$ ，为 降水最少年份，流域降水量整体以 $3.14 \mathrm{~mm} / \mathrm{a}$ 的速度减少。以上数据显示，南洞地下河 流域在 1980 年降水量最小、蒸散量最大并且径流量也为多年最小，这很好地反映出气候 变化对南洞流域径流量的影响。但是流域最大降雨量年份、最小蒸散量年份与最大径流 
量年份却不相同，这表明南洞地下河 流域气候变化下降水量、蒸散量变化 趋势与径流量变化趋势并不完全一 致, 可见人类活动对径流的变化具有 不可忽视的影响。

\section{2 径流量与降水量突变年份分析}

采用有序聚类法对南洞地下河流 域降水（以降水为气候变化的代表, 不再单独对蒸散量进行突变分析）、 径流量做突变分析, 通过计算得到突 变点 $T$ 前后的离差平方和的和 $S(T)$ 值，相应的 $S(T)$ 值变化情况如图 3 所 示。其中降水 $S(T)$ 值存在三个明显的 极小值, 且 2008 年为最小值, 按照 有序聚类法使 $S(T)$ 值为极小值时所对 应的序列的变异点, 并以此对序列进 行划分的原则，可以找到南洞地下河 流域降水的三个突变点, 即 1986年、 2002 年、 2008 年，其中 2008 年突变 趋势最显著。径流 $S(T)$ 值也呈现出三 个明显的极小值, 2009 年为最小值, 因此可以确定径流的突变点为 1979 年、 2002 年、 2009 年，其中 2009 年 突变趋势最显著。径流和降水的突变 年份虽然不完全一致，但是存在 2002 年这个相同年份和 2008 年、 2009 年 两个相近的年份，并且地下水对降水 响应有一定的延迟，所以可以较好地 理解这个时期径流降水突变点出现的 时间差异。

根据 Mann-Kendall法，对南洞地 下河流域径流和降水变化进行分析。 将算得的降水和径流的统计值 $U F_{K}$ 和 $U B_{K}$ 绘成曲线, 并添加显著性 $\alpha=0.05$, $U_{0.05}= \pm 1.96$ 时的置信边界线。在置信 区间内的 $U F_{K}$ 和 $U B_{K}$ 曲线交点，即为 突变的开始。从图 4 可知, 用 MannKendall 法找到的降水突变年份为 2004 年。但是径流的突变年份较多, 除了 1986 年和 2002 年，在早期短时

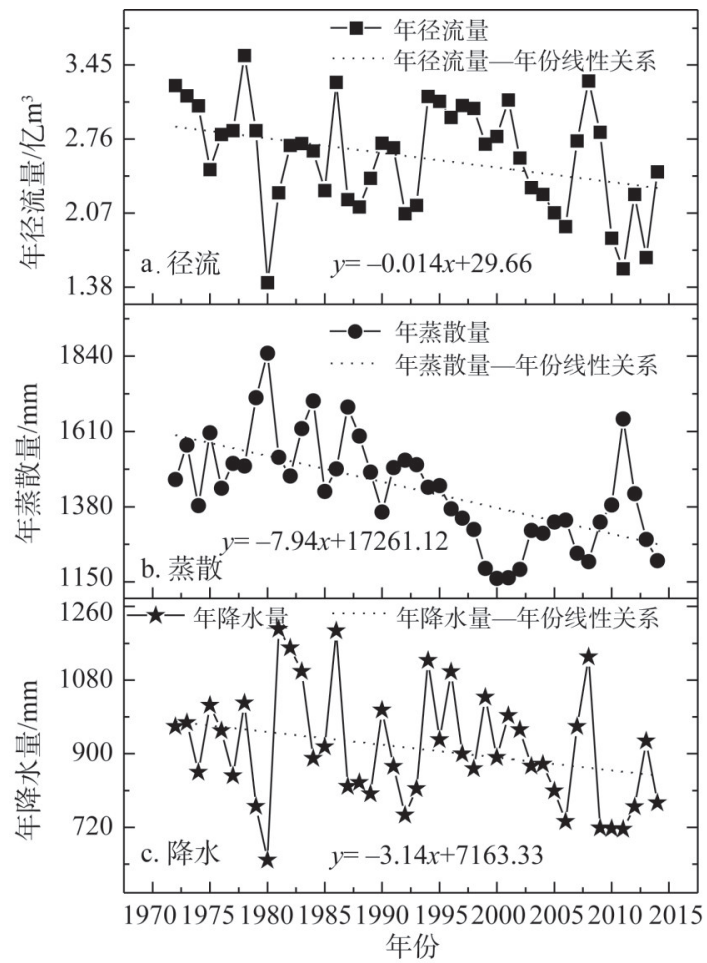

图2 南洞地下河流域 1972-2014年降水量、 年径流量、年蒸散量变化

Fig. 2 Interannual variations of precipitation and flow and evapotranspiration in Nandong subterranean river catchment during 1972-2014
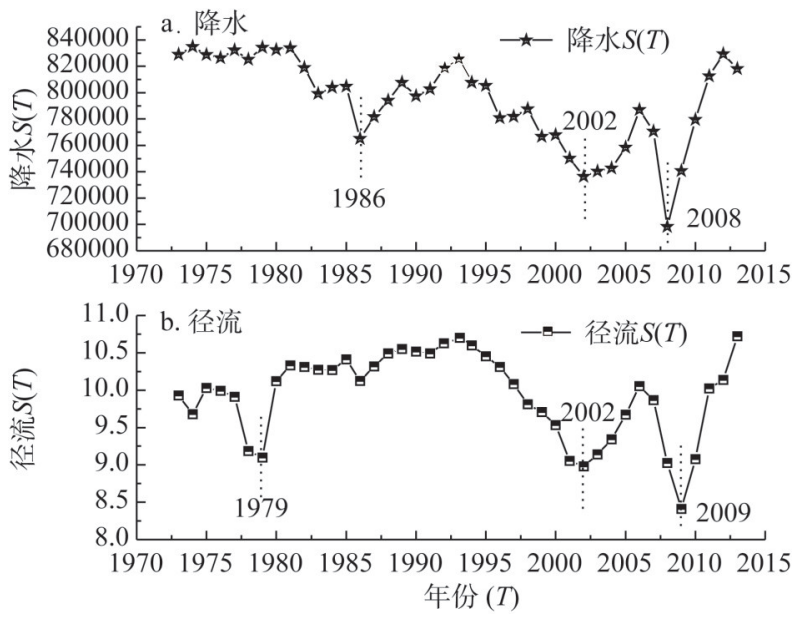

图 3 基于有序聚类分析法的南洞地下河流域 径流与降水 $S(T)$ 值变化过程

Fig. $3 S(T)$ change process based on the sequential clustering method for the annual precipitation and flow series in the Nandong subterranean river catchement 
间内还有多个突变点。

依据有序聚类法找到的南洞地 下河流域径流和降水突变趋势最明 显的时间分别是 2009 年、2008 年, 其次是 2002 年。根据 Mann-Kendall 法找到的径流和降水的突变年份有 2002 年和 2004 年。虽然两种检测方 法结果并不完全一致，但是综合两 种方法和南洞流域实际人类活动情 况, 以 2002 年和 2008 年为突变点, 将流域内径流、降水和蒸散变化情 况划分为三个时期。其中 1972-2002 年为人类活动影响较小、径流变化 主要受气候变化影响的基准期 $\left(\mathrm{T}_{1}\right) ； 2002$ 年后人类活动的影响逐 渐表现，并与气候因素共同作用于 径流变化，这一时期称为措施期。
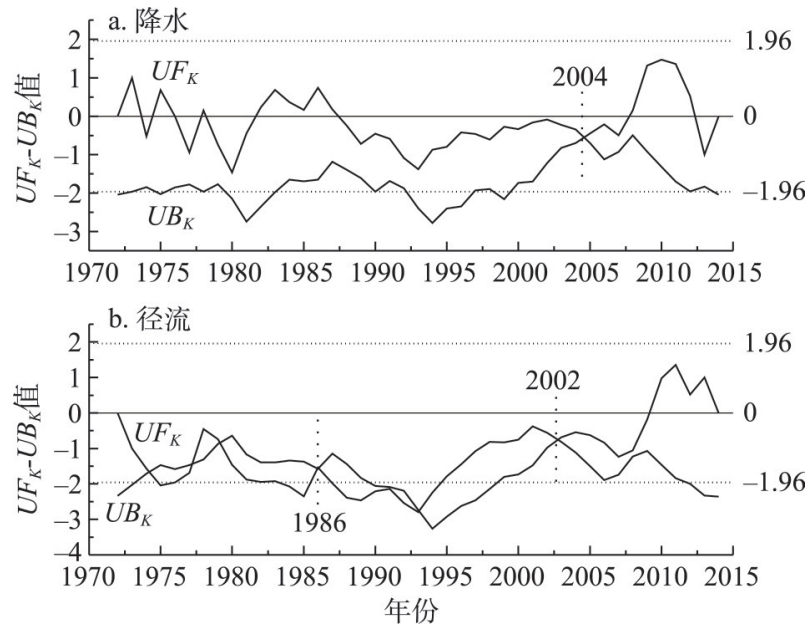

图 4 基于 Mann-Kendall法的南洞地下河流域 降水和径流 $U F_{K}-U B_{K}$ 值变化过程

Fig. $4 U F_{K}$ and $U B_{K}$ change process based on Mann-Kendall test method for the annual precipitation and flow series in the Nandong subterranean river catchement 由于人类活动作用程度的不同，措施期又具体划分为两个阶段： $T_{2}$ 为 2003-2008年， $T_{3}$ 为 2009-2014年。

\section{3 气候变化与人类活动贡献率分解}

依据上述有序聚类法和Mann-Kendall法综合确定的拐点以及划分出的时期，分别对累 积的降水量、径流量和蒸散量与年份进行线性拟合，最后拟合出的关系式如图 5。各拟合 关系式的相关系数 $(R)$ 都非常高, $R^{2}$ 都在 0.99 以上, 并且对应的 $P$ 都小于 0.01 , 表明其显 著度高, 拟合结果好。将各方程的斜率总结至表 1 。若改变率为正说明变量呈增长趋 势, 改变率为负说明变量呈减少趋势。降水累积量和蒸散累积量的斜率改变量, 相对于 径流累积量斜率改变量的比例, 即为降水和蒸散量变化对径流变化的贡献率 ${ }^{[3,5,10]}$ 。这个贡 献率是指对径流量实际发生变化部分的贡献率，而不是对总径流量的贡献率 ${ }^{\left[{ }^{[}\right]}$。

$\mathrm{T}_{1} 、 \mathrm{~T}_{2}$ 时期累积降水一年份线性拟合方程的斜率分别为 $939.91 \mathrm{~mm} / \mathrm{a} 、 881.88 \mathrm{~mm} / \mathrm{a}$, 与 $T_{1}$ 相比, $T_{2}$ 时期降水累积斜率改变率为 $-6.17 \%$, 说明 $T_{2}$ 时期相对于 $T_{1}$ 时期降水减少。 $\mathrm{T}_{1} 、 \mathrm{~T}_{2}$ 时期累积径流一年份线性拟合方程的斜率分别为 2.63 亿 $\mathrm{m}^{3} / \mathrm{a} 、 2.39$ 亿 $\mathrm{m}^{3} / \mathrm{a}$ ，与基准 期 $\mathrm{T}_{1}$ 相比， $\mathrm{T}_{2}$ 时期径流累积斜率改变率为 $-9.13 \%$ ，表明相对于 $\mathrm{T}_{1}$ 时期， $\mathrm{T}_{2}$ 时期径流减 少。 $\mathrm{T}_{1} 、 \mathrm{~T}_{2}$ 时期累积蒸散量一年份线性拟合方程的斜率分别为 $1502.56 \mathrm{~mm} / \mathrm{a}$ 、 $1290.94 \mathrm{~mm} / \mathrm{a}$ ，与 $\mathrm{T}_{1}$ 时期相比 $\mathrm{T}_{2}$ 时期累积蒸散量的斜率改变率为 $-14.08 \%$, 说明 $\mathrm{T}_{2}$ 时期 相对与 $\mathrm{T}_{1}$ 时期蒸散量减少。以上说明，相对于基准期 $\mathrm{T}_{1}, \mathrm{~T}_{2}$ 时期的累积径流、降水量和蒸 散量都呈减少趋势，且累积蒸散量的减少率最大。根据式（6）～式（9）计算得到各因素对 径流变化的贡献率（表2)。如果只考虑降水变化对径流变化的影响，此时降水对径流变化 的贡献率为 $67.66 \%$ ，而人类活动对径流变化的贡献率则为 $32.34 \%$ 。由于南洞地下河流域 实测蒸散量明显大于降雨量, 因此不可忽视蒸散量的变化对径流的影响。降雨会带来径流 量的补给，而蒸散则造成径流量的消耗。如果综合考虑降水和蒸散的共同影响，那么气候 变化对径流变化的贡献率将减小，而人类活动的贡献率将增加。 $\mathrm{T}_{2}$ 与 $\mathrm{T}_{1}$ 时期相比，降水 
虽然减少了 $6.17 \%$ ，但是蒸散也减少了 $14.08 \%$ ，蒸散量减少的比例更大，如果没 有人类活动参与，此时的流域内径流相比 前一阶段应该是增加趋势，但此时流域内 径流减少了 $9.13 \%$ ，说明人类活动才是这 一时期径流减少的原因。具体气候变化对 降水减少的贡献率为 $-86.68 \%$, 而人类活 动对降水减少的贡献率为 $186.68 \%$ 。

同理 $\mathrm{T}_{3}$ 与 $\mathrm{T}_{1}$ 时期相比，累积降水量 斜率减少率为 $16.14 \%$, 累积径流量斜率 减少率为 $27.00 \%$, 累积蒸散量斜率减少 率为 $6.44 \%$ （表 1 ）。可见 $\mathrm{T}_{3}$ 时期与基准期 相比径流、降水和蒸散量也为减少趋势, 且径流的减少幅度最大。通过累积量斜率 变化率比较法算得结果, 若不考虑潜在蒸 散量的影响，相对于 $T_{1}$ 时期， $T_{3}$ 时期降水 减少对径流减少的贡献为 $59.79 \%$ ，人类 活动对径流变化的贡献为 $40.21 \%$ 。如果 考虑到蒸散量影响, 气候变化对径流减少 的贡献率为 $35.92 \%$ ，人类活动对径流变 化的贡献率为 $64.08 \%$ 。

综上所述，南洞地下河流域措施期 （2003-2014年），人类活动对径流变化的 贡献率在 $64.08 \%$ 186.68\% 之间，远大于

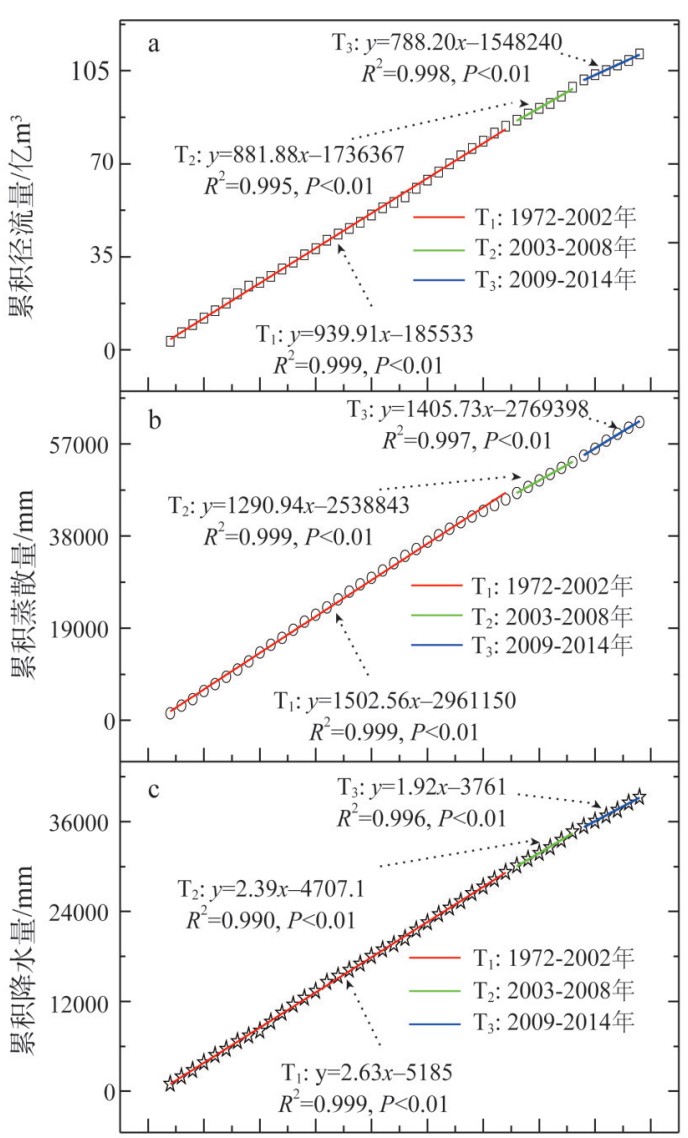

1970197519801985199019952000200520102015

图 5 累积量变化趋势

Fig. 5 Interannual variations of accumulative factors 气候变化（降水和蒸散量变化）对径流减少的贡献率。虽然 $\mathrm{T}_{3}$ 时期人类活动贡献率明显 下降，但是人类活动依然是南洞地下河流域径流变化的主要驱动因素。

\section{4 人类活动分析}

以上研究表明，人类活动是南洞地下河流域径流变化的主导因素。人类活动可直接 或间接影响径流量变化，一方面人口数量增加、经济活动增强直接带来生产生活用水量 的增加使径流量减少; 另一方面农业生产、道路交通和城市建设等经济活动通过改变土 地利用/土地覆被，进而改变地表人渗、汇流和补给等过程，间接影响径流量 ${ }^{[26-27]}$ 。

\section{4 .1 土地利用变化}

为了解南洞地下河流域土地利用/土地覆被的变化情况，利用研究区 1990 年、1995

表 1 不同时期年份与各累积量斜率及其变化

Table 1 Slope change ratio of cumulative quantity in different periods

\begin{tabular}{|c|c|c|c|c|c|c|}
\hline \multirow{2}{*}{$\begin{array}{l}\text { 时期 } \\
\text { /年 }\end{array}$} & \multicolumn{3}{|c|}{ 累积量斜率 } & \multicolumn{3}{|c|}{ 斜率改变率 } \\
\hline & 降水/(mm/a) & 径流/(亿 $\left.\mathrm{m}^{3} / \mathrm{a}\right)$ & 蒸散/(mm/a) & 降水/\% & 径流/\% & 蒸散/\% \\
\hline $\mathrm{T}_{1}: 1972-2002$ & 939.91 & 2.63 & 1502.56 & - & - & - \\
\hline $\mathrm{T}_{2}: 2003-2008$ & 881.88 & 2.39 & 1290.94 & -6.17 & -9.13 & -14.08 \\
\hline $\mathrm{T}_{3}: 2009-2014$ & 788.20 & 1.92 & 1405.73 & -16.14 & -27.00 & -6.44 \\
\hline
\end{tabular}


年、 2000 年、 2005 年和 2010 年 5 期 地表反射率合成产品（Landsat 7 $\mathrm{ETM}+/$ Landsat $8 \mathrm{OLI})$ ，并运用最大 似然监督分类方法将研究区土地覆盖 类型划分为耕地、森林、草地、水体 和建设用地 5 类 ${ }^{[28]}$ 。得到分类结果, 整理于表 3。结果显示 1990-2000 年 间南洞地下河流域的耕地所占面积从 $30.39 \%$ 减少为 $29.69 \%$ ，建设用地面 积比例略有增长，十年之间耕地面积 和建设用地面积占比变化不足 1 个百 分点。同期森林面积比例保持在 $27.31 \%$ ，草地面积比例维持在 $37.35 \%$ ，水体面积比例保持在 $2.51 \%$ 。可见在 1990-2000年间南洞地 下河流域范围内，耕地和建设用地面 积有轻微变化（耕地比例减少
表 2 气候与人类活动对径流量变化的贡献

Table 2 Contributions of climate and human activities to the changes of flow

\begin{tabular}{ccccc}
\hline \multirow{2}{*}{ 时期/年 } & \multicolumn{5}{c}{ 贡献率/\% } \\
\cline { 2 - 5 } & 降水 & 蒸散 & 气候变化 & 人类活动 \\
\hline $\mathrm{T}_{1}: 1972-2002$ & - & - & - & - \\
$\mathrm{T}_{2}: 2003-2008$ & 67.66 & -154.34 & -86.68 & 186.68 \\
$\mathrm{~T}_{3}: 2009-2014$ & 59.79 & -23.87 & 35.92 & 64.08 \\
\hline
\end{tabular}

\section{表 $3 \quad 1990-2010$ 年南洞地下河流域土地利用结构}

Table 3 Proportion of land use types in Nandong subterranean river catchment during 1990-2010

$(\%)$

\begin{tabular}{cccccc}
\hline 土地利用 & 1990 年 & 1995年 & 2000 年 & 2005 年 & 2010 年 \\
\cline { 2 - 6 } 型 & 比例 & 比例 & 比例 & 比例 & 比例 \\
\hline 耕地 & 30.39 & 30.04 & 29.69 & 40.31 & 50.07 \\
森林 & 27.31 & 27.31 & 27.31 & 14.60 & 13.43 \\
草地 & 37.35 & 37.35 & 37.35 & 39.08 & 30.43 \\
水体 & 2.51 & 2.51 & 2.51 & 2.70 & 2.45 \\
建设用地 & 2.44 & 2.79 & 3.14 & 3.31 & 3.62 \\
\hline
\end{tabular}
$0.7 \%$, 建设用地面积增加 $0.7 \%$ ), 而森林、草地和水体这三种土地类型所占比例保持不 变。从土地利用/土地覆被变化的情况来看，1990-2000年间人类活动对土地利用的改变 极小，因此也证明将 1972-2002 年划分为几乎无人类活动影响的基准期的合理性。

2000-2010年间，南洞地下河流域范围内耕地和森林面积比例发生剧烈变化。20002005 年间耕地面积比例增加 $10.62 \%$ ，同期森林面积比例减少 $12.71 \%$ ，与 2000 年前相比 森林面积比例约减少一半，其他土地利用类型变化幅度较小。可见这一时期，人类活动 对森林破坏严重，大量林地转为耕地。森林破坏带来严重的生态环境问题，典型的是流域 内水土流失情况日趋严重，进而导致流域下垫面特征改变，径流量发生变化。2005-2010 年间耕地面积增加了 $9.76 \%$ 。同期，由于一系列生态保护措施的实施 ${ }^{[29-30]}$ ，森林破坏得到 有效控制，减少了 $1.17 \%$ ，但是草地破坏依然严重，减少面积比例高达 $8.65 \%$ ，这一时期 人类活动的表现主要是将草地开垦为耕地。到 2010 年耕地面积比例已达 $50.07 \%$, 超过所 有土地类型总面积的一半，耕地所需灌溉用水量必然增加，加大当地水资源压力。在此 期间，虽然建设用地面积占所有土地类型的比例较小，但是一直呈增长趋势。2000-2010 年间，人类活动对土地利用/土地覆被的改造力度巨大，虽然后期加强了生态环境的保 护，但是人类活动的影响力依然显著。

\subsection{2 人口与经济活动变化}

由于流域范围涉及个旧、开远和蒙自三个行政区，并且个旧、开远在流域内的面积 较小, 蒙自所占流域面积最大，因此以蒙自为代表，利用蒙自人口经济变化数据，反映 流域内人口经济的变化情况。根据 1995-2014年《蒙自年鉴》 ${ }^{[31]}$ 资料，2003 年红河州政府 驻地由个旧市迁移至蒙自县，蒙自经济开始迅速发展。伴随州政府的搬迁，需要大规模 的市政建设。从蒙自经济资料分析可知（图 6)，2002年前，蒙自固定资产投资总额较 小，且增长缓慢，2002 年后固定资产投资额度大幅增加。2005 年后市政建设基本结束， 固定资产投资增长幅度略微下降，但仍然呈高速增长趋势（图 6a）。固定资产投资中基本 
建设和房地产投资占 $80 \%$ 左右, 这将使 地面硬化, 减少人渗。2002 年前蒙自 GDP 总额较小, 且增长幅度约为 $8.92 \%, 2002$ 年后 GDP 值持续高速增 加, 平均增长率高达 $21.72 \%$, 反映出经 济的快速发展（图 6b)。固定资产投资增 长率和 GDP 增长率的变化间接反映出, 州政府搬迁到流域内, 一系列经济活动 加剧了对流域环境的影响。同时，从人 口数量来看, 蒙自市人口一直呈增长趋 势。经统计 1995-2002年间, 蒙自人口自 然增长率平均为 $1.13 \%$, 而 2003-2014 年 间蒙自人口自然增长率平均为 $1.71 \%$ 。一 方面人口基数的不断增长，加上人口自 然增长率上升, 造成居民生活生产用水 量的剧增。另一方面人口数量增长, 对 耕地资源、住房面积的需求也将增大, 这也解释了 2000 年后南洞地下河流域森 林和草地面积大幅下降, 而耕地面积、 城市建设用地面积持续增加。森林面积 的大量减少不利于流域内水土保持与调

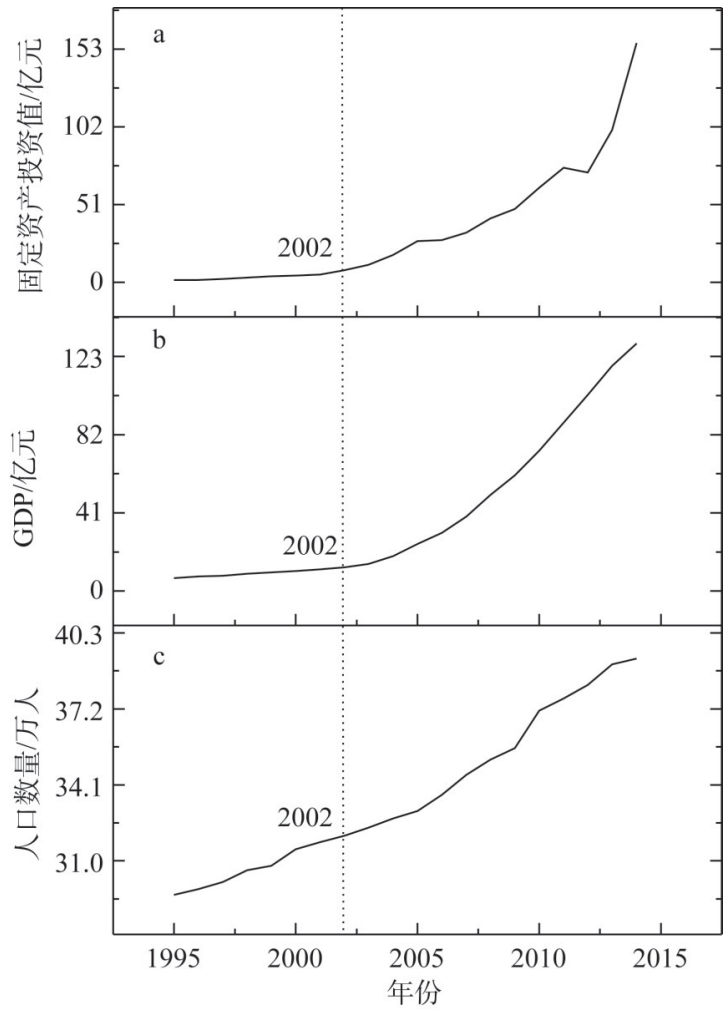

图 6 1995-2014年蒙自经济趋势

Fig. 6 Economic trends of Mengzi during 1995-2014

蓄。同时耕地面积也迅速增加至 $40.34 \%$ ，导致农业用水量增加。因此， $\mathrm{T}_{2}$ 时期人类活动 对径流减少的贡献率达 $186.68 \%$ 。

$\mathrm{T}_{3}$ 阶段人类活动贡献率下降至 $64.08 \%$ ，一方面人类活动干预减弱、生态环境治理初 见成效。由于 $\mathrm{T}_{2}$ 阶段剧烈的人类活动, 加剧流域内生态环境的恶化。南洞地下河流域是 典型岩溶地下河流域，生态环境脆弱，石漠化严重，人地矛盾突出 ${ }^{[17,19]}$, 州政府搬迁带来 了经济发展，同时带来生态环境的挑战。2006年石漠化综合治理工作全面开始 ${ }^{[29-30]}$, 流 域内进行生态恢复与重建，森林退化得到有效控制，生态环境逐渐转好。另一方面 2008 年后, 云南省极端气候事件频发, 出现连续多年的干旱 ${ }^{[1-32]}$, 降雨明显减少，与 $\mathrm{T}_{1}$ 时期相 比，气候变化对径流减少的贡献率为 $35.92 \%$, 远高于 $\mathrm{T}_{2}$ 时期，但是干旱也对居民生产生 活造成巨大影响，为了生计不得不继续对地下水资源进行开采，资料显示仅 2011 年水 利、国土部门组织抗早应急打井 1029 眼, 出水量达 $3000 \mathrm{~m}^{3} / \mathrm{d}^{[31]}$, 因此在此阶段人类活动 依旧是径流减少的主要原因。

\section{3 结论}

本文利用南洞地下河流域1972-2014年的径流量、降水量和蒸散量数据, 分析其变化 特征，并利用有序聚类法、Mann-Kendall法划分降水和径流变化不同时期，利用累积量 斜率变化率比较法定量分解不同时期气候与人类活动变化对径流变化的贡献率, 最终得 到以下结论： 
（1）南洞地下河流域1972-2014年径流量、蒸散量和降水量均呈波动减少趋势。其中 流域内径流整体以 0.014 亿 $\mathrm{m}^{3} / \mathrm{a}$ 的速度减少，流域内降水整体以 $3.14 \mathrm{~mm} / \mathrm{a}$ 的速度减少，蒸 散整体以 $7.94 \mathrm{~mm} / \mathrm{a}$ 的速度减少。

（2）采用有序聚类法、Mann-Kendall法综合确定流域径流和降水的拐点有两个，分 别为 2002 年和 2008 年。

（3）以人类活动轻微的 $T_{1}$ （1972-2002年）阶段为基准期，综合考虑降水和蒸散量的 影响。 $\mathrm{T}_{2}$ （2003-2008年）阶段气候变化对径流减少的贡献率为-86.68\%, 而红河州州政 府搬迁及系列经济活动带来的人口增加、土地利用变化对径流减少的贡献率达 $186.68 \%$ 。 $\mathrm{T}_{3}$ （2009-2014年）阶段气候变化对径流减少的贡献率为 $35.92 \%$ ，而石漠化综 合治理等生态保护工作使人类活动对径流减少的贡献率相对减小，但是由于多年干早、 抗早打井开采地下水，人类活动依然是此阶段径流减少的主要原因，贡献率达 $64.08 \%$ 。

（4）人类活动是南洞地下河流域径流量年际变化的主导因素，其中生活、生产的直 接耗水和土地利用/土地覆被变化影响下径流过程的变化，共同影响着径流年际变化。

致谢：感谢李丽硕士、姜峰硕士在降雨、水文数据收集和整理方面给予的大力帮助!

\section{参考文献(References):}

[1] WU P, CHRISTIDIS N, STOTT P. Anthropogenic impact on earth's hydrological cycle. Nature Climate Change, 2013, 3 : 807-810.

[2] 李峰平, 章光新, 董李勤. 气候变化对水循环与水资源的影响研究综述. 地理科学, 2013, 33(4): 457-464. [LI F P, ZHANG G X, DONG L Q. Studies for impact of climate change on hydrology and water resources. Scientia Geographica Sinica, 2013, 33(4): 457-464.]

[3] 王随继, 间云霞, 颜明, 等. 皇甫川流域降水和人类活动对径流量变化的贡献率分析: 累积量斜率变化率比较方法的 提出及应用. 地理学报, 2012, 67(3): 388-397. [WANG S J, YAN Y X, YAN M, et al. Contributions of precipitation and human activities to the runoff change of the Huangfuchuan Drainage Basin: Application of comparative method of the slope changing ratio of cumulative quantity. Acta Geographica Sinica, 2012, 67(3): 388-397.]

[4] 董否华, 熊立华, 于坤霞, 等. 气候变化与人类活动对水文影响的研究进展. 水科学进展, 2012, 23(2): 278-285. [DONG L H, XIONG L H, YU K X, et al. Research advances in effects of climate change and human activities on hydrology. Advances in Water Science, 2012, 23(2): 278-285.]

[5] 王彦君, 王随继, 苏腾. 降水和人类活动对松花江径流量变化的贡献率. 自然资源学报, 2015, 30(2): 304-314. [WANG Y J, WANG S J, SU T. Contributions of precipitation and human activities to runoff change in the Songhua River Basin. Journal of Natural Resources, 2015, 30(2): 304-314.]

[6] 赵安周, 赵玉玲, 刘宪锋, 等. 气候变化和人类活动对渭河流域蓝水绿水影响研. 地理科学, 2016, 36(4): 571-579. [ZHAO A Z, ZHAO Y L, LIU X F, et al. Impact of human activities and climate variability on green and blue water resources in the Weihe River Basin of Northwest China. Scientia Geographica Sinica, 2016, 36(4): 571-579.]

[7] VOROSMARTY C J, GREEN P, SALISBURY J. Global water resources: Vulnerability from climate change and population growth. Science, 2000, 289(5477): 284-288.

[8] LI Z W, XU X L, YU B F, et al. Quantifying the impacts of climate and human activities on water and sediment discharge in a karst region of Southwest China. Journal of Hydrology, 2016, 542: 836-849.

[9] BATOOL A, AMIR A K, AMIN A, et al. Quantifying anthropogenic stress on groundwater resources. Scientific Report, 2017, 7(1): 1-9.

[10] 徐森, 狄崇利, 李思亮. 典型喀斯特流域降水与径流特征分析及径流年际变化的影响因素贡献分解. 第四纪研究, 2017, 37(6): 1238-1250. [XU S, DI C L, LI S L. Analysis of characteristics of precipitation and runoff in the typical karst catchment and contribution decomposition on influencing factors of interannual runoff variation. Quaternary Sciences, 2017, 37(6): 1238-1250.]

[11] CHOU V T. Applied Hydrology. New York: McGraw-Hill Higher Education, 1988.

[12] 袁道先. 中国岩溶学. 北京: 地质出版社, 1994. [YUAN D X. Karstology in China. Beijing: Geological Press, 1994.] 
[13] 袁道先. 对南方岩溶石山地区地下水资源生态环境地质调查的一些意见. 中国岩溶, 2000, 19(2): 103-108. [YUAN D X. Aspects on the new round land and resources survey in karst rock desertification areas of South China. Carsologica Sinica, 2000, 19(2): 103-108.]

[14] 李小雁, 马育军. 地球关键带科学与水文土壤学研究进展. 北京师范大学学报: 自然科学版, 2016, 52(6): $731-737$. [LI X Y, MA Y J. Advances in earth's critical zone science and hydropedology. Journal of Beijing Normal University: Natural Sciences, 2016, 52(6): 731-737.]

[15] 王随继, 李玲, 颜明. 气候和人类活动对黄河中游区间产流量变化的贡献率. 地理研究, 2013, 32(3): $395-402$. [WANG S J, LI L, YAN M. The contributions of climate change and human activities to the runoff yield changes in the middle Yellow River Basin. Geographical Research, 2013, 32(3): 395-402.]

[16] 康彦仁. 云南南洞地下河系统及水资源开发利用. 中国岩溶, 1993, 12(4): 307-318. [KANG Y R. Water resource development of Nandong subterranean stream system Yunnan province. Carsologica Sinica, 1993, 12(4): 307-318.]

[17] 马祖陆. 云南南洞地下河流域地貌特征及地下河发育演化的初步研究. 中国岩溶, 1993, 12(3): 92-102. [MA Z L. Preliminary study on the geomorphology and its evolution of Nandong River Basin, Yunnan province. Carsologica Sinica, 1993, 12(3): 92-102.]

[18] 赵一, 李衍青, 覃星铭, 等. 南洞地下河岩溶管道展布及结构特征的示踪试验解. 中国岩溶, 2017, 36(2): $226-233$. [ZHAO Y, LI Y Q, QIN X M, et al. Tracer tests on distribution and structural characteristics of karst channels in Nandong underground river drainage. Carsologica Sinica, 2017,36(2): 226-233.]

[19] 覃星铭, 蒋忠诚, 何丙辉, 等. 南洞流域东部重点区石漠化现状及治理对策. 中国岩溶, 2014, 33(4): 456-463. [QIN X M, JIANG Z C, HE B H, et al. Current status and treatment of rocky desertification in key eastern areas of the Nandong subterranean river system. Carsologica Sinica, 2014, 33(4): 456-463.]

[20] JIANG Y J, WU X, CHRIS G, et al. Natural and anthropogenic factors affecting the groundwater quality in the Nandong karst underground river system in Yunan, China. Journal of Contaminant Hydrology, 2009, 109(1): 49-61.

[21] 覃星铭, 蒋忠诚, 蓝芙宁, 等. 南洞地下河月径流时间序列的混沌特征及预测. 中国岩溶, 2015, 34(4): 341-347. [QIN X M, JIANG Z C, LAN F N, et al. Chaos analysis and prediction of monthly runoff time series in the Nandong subterranean river. Carsologica Sinica, 2015, 34(4): 341-347.]

[22] 罗书文, 黄保健, 李成展, 等. 南洞地下河水文地球化学特征及径流量识别. 中国农村水利水电, 2016, (2): 82-86. [LUO S W, HUANG B J, LI C Z, et al. Research on hydro-geochemical characteristics and identification runoff of Nandong underground river. China Rural Water and Hydropower, 2016, (2): 82-86.]

[23] 莫美仙. 云南南洞地下河系统边界及结构特征研究. 昆明: 昆明理工大学, 2017. [MO M X. Research on the boundary and structural ccharacteristics of Nandong underground river system in Yunnan. Kunming: Kunming University of Science and Technology, 2017.]

[24] 袁满, 王文圣, 叶濒璘. 有序聚类分析法的改进及其在水文序列突变点识别中的应用. 水文, 2017, 37(5): 8-11. [YUAN M, WANG W S, YE B L. Improvement of sequential clustering method and its application to diagnose jump points of hydrological series. Jouranal of China Hydrology, 2017, 37(5): 8-11.]

[25] 黄嘉佑, 李庆祥. 气象数据统计分析方法. 北京: 气象出版社, 2015: 49-69. [HUANG J Y, LI Q X. Meteorological Data Statistical and Analysis Method. Beijing: China Meteorological Press, 2015: 49-69.]

[26] 李丽娟, 姜德娟, 李九一, 等. 土地利用/覆被变化的水文效应研究进展. 自然资源学报, 2007, 22(2): 211-224. [LI L J, JANG D J, LI J Y, et al. Advances in hydrological response to land use/land cover change. Journal of Natural Resources, 2007, 22(2): 211-224.]

[27] 戴明宏, 张军以, 王腊春, 等. 岩溶地区土地利用/覆被变化的水文效应研究进展. 生态科学, 2015, 34(3): 189-196. [DAI M H, ZHANG J Y, WANG L C, et al. A review on impacts of land use/land cover change on water resources in karst areas. Ecological Science, 2015, 34(3): 189-196.]

[28] 邓树斌. ENVI遥感图像处理方法. 北京: 科学出版社, 2010. [DENG S B. ENVI Remote Sensing Image Processing Method. Beijing: Science Rress, 2010.]

[29] 王宇, 张华, 张贵. 云南省石漠化调查及治理综述. 中国岩溶, 2016, 35(5): 486-496. [WANG Y, ZHANG H, ZHANG $\mathrm{G}$, et al. Review of the investigation and integrated renovation on rocky desertification in Yunnan province, China. Carsologica Sinica, 2016, 35(5): 486-496.]

[30] 蒋忠诚, 罗为群, 童立强, 等. 21 世纪西南岩溶石漠化演变特点及影响因素. 中国岩溶, 2016, 35(5): 461-468. [JIANG Z C, LUO W Q, TONG L Q, et al. Evolution features of rocky desertification and influence factors in karst areas of Southwest China in the $21^{\text {th }}$ century. Carsologica Sinica, 2016, 35(5): 461-468.]

[31] 李运良. 蒙自年鉴. 德宏: 德宏民族出版社, 2015. [LI Y L. Mengzi Yearbook. Dehong: Dehong National Press, 2015.]

[32] 付奔, 胡关东, 杨帆, 等. 云南干旱 “常态化” 的分析. 水文, 2014, 34(4): 82-85. [FU B, HU G D, YANG F, et al. Analysis of drought normalization in Yunnan province. Journal of China Hydrology, 2014, 34(4): 82-85.] 


\title{
Impacts of climate change and human activities on the interannual flow changes in a typical karst subterranean river, South China
}

\author{
WANG Sai-nan ${ }^{1,2}$, LI Jian-hong ${ }^{2}$, PU Jun-bing ${ }^{2}$, HUO Wei-jie ${ }^{2}$, \\ ZHANG Tao ${ }^{2}$, HUANG Si-yu², YUAN Dao-xian ${ }^{1,2}$ \\ (1. Chongqing Key Laboratory of Karst Environment, School of Geography Sciences, Southwest University, \\ Chongqing 400715, China; 2. Key Laboratory of Karst Dynamics, Ministry of Natural Resources, Institute of \\ Karst Geology, Chinese Academy of Geological Sciences, Guilin 541004, Guangxi, China)
}

\begin{abstract}
Quantifying the impacts of climate change and human activities on runoff changes is one of challenges in hydrology and water resources researches. In order to reveal the impacts of climate change and human activities on the interannual flow of a karst subterranean river system, this study chose a big karst subterranean river in south China, Nandong subterranean river (NSR) as a research area to analyse the interannual variations of precipitation, evapotranspiration and flow based on the data of flow, evapotranspiration and precipitation of NSR from 1972 to 2014. The results indicated that precipitation, evapotranspiration and flow of NSR during the study period showed a fluctuating decline trend, in which the overall declining rates of precipitation, evapotranspiration and flow were $3.14 \mathrm{~mm} / \mathrm{a}, 7.49 \mathrm{~mm} / \mathrm{a}$ and $0.014 \times 10^{8}$ $\mathrm{m}^{3} / \mathrm{a}$, respectively. Two inflection-point years in the variations of precipitation and flow, 2002 and 2008 were identified through the sequential clustering and Mann-Kendall test methods. The method of slope changing ratio of cumulative quantity was adopted in estimation of the contributions of climate change and human activities to the flow variations in NSR. Considering the influence of evapotranspiration in NSR, the results, with 1972-2002 as the base period, indicated less effect from human activities. The contribution rates of the climate changes to the flow changes were $-86.68 \%$ in the $\mathrm{T}_{2}$ period $(2003-2008)$, and $35.92 \%$ in the $\mathrm{T}_{3}$ period (2009-2014), while the contribution rates of human activities were $186.68 \%$ in the $\mathrm{T}_{2}$ period and $64.08 \%$ in the $\mathrm{T}_{3}$ period. Obviously, human activities were the dominant factor causing the interannual flow change in NSR catchment. Direct water consumption of production and living and the changes of flow processes under the influences of land use/land cover changes exerted a main influence on the interannual flow changes. The results can give us a better understanding of the variation characteristics under the impacts of climate change and human activities and help to reasonably regulate karst water resources.
\end{abstract}

Keywords: climate change; human activities; flow; slope changing ratio of cumulative quantity; Nandong subterranean river 